\title{
NEDD4L on human chromosome 18q21 has multiple forms of transcripts and is a homologue of the mouse Nedd4-2 gene.
}

\author{
Haiming Chen ${ }^{* 1}$, Christopher A Ross ${ }^{1,2}$, Nulang Wang ${ }^{1}$, Yuqing Huo ${ }^{1}$, Dean F MacKinnon ${ }^{1}$, \\ James B Potash ${ }^{1}$, Sylvia G Simpson ${ }^{1}$, Francis J McMahon ${ }^{3}$, J Raymond DePaulo, Jr ${ }^{1}$ and \\ Melvin G McInnis*,1 \\ ${ }^{1}$ Department of Psychiatry and Behavioral Sciences, Johns Hopkins University School of Medicine, Baltimore, \\ Maryland, MD 21287, USA; ${ }^{2}$ Department of Neuroscience, Johns Hopkins University School of Medicine, \\ Baltimore, Maryland, MD 21287, USA; ${ }^{3}$ Department of Psychiatry, University of Chicago, Chicago, IL60637, USA
}

The validation of full-length cDNA represents a crucial step in gene identification and subsequent functional analysis. In searching for candidate genes for bipolar disorder on chromosome 18q21, a novel gene homologous to NEDD4 (Neural precursor cells expressed developmentally down-regulated) was identified using exon trapping and cDNA cloning. This novel gene is termed NEDD4L (Human Gene Nomenclature Committee symbol). Typical NEDD4 orthologues that contain a $\mathrm{C2}\left(\mathrm{Ca}^{2+} /\right.$ lipid-binding) and a $\mathrm{HECT}$ (Homologous to the E6-AP Carboxyl Terminus) ubiquitin-protein ligase domain, and multiple WW domains have been shown to regulate the epithelial sodium channel ( $E N a C$ ). In mice, Nedd4 has two distinct isoforms termed Nedd4-1 that belongs to the typical NEDD4 class, and Nedd4-2 that is homologous to Nedd4-1 but lacks the C2 domain. NEDD4L contains the WW and HECT domains seen in the NEDD4 gene family, but lacks the C2 domain in the $\mathrm{N}$-terminus. BLAST database search showed that the deduced polypeptide of NEDD4L has 97 and $62 \%$ sequence identity to mouse Nedd4-2 and human NEDD4, respectively. Multiple forms of transcripts of NEDD4L have been isolated, which differ in transcription start and termination sites together with the presence or absence of an alternative spliced exon. Northern blot analysis showed a $3.4 \mathrm{~kb}$ mRNA species was specifically expressed in heart and skeletal muscle, while a $3.2 \mathrm{~kb}$ band and/or an additional $3.6 \mathrm{~kb}$ band is seen in other tissues tested. Striking homology of NEDD4L to mouse Nedd4-2 suggests it is the human homologue of mouse Nedd4-2. Its position in a region of linkage for autosomal dominant orthostatic hypotensive disorder and its potential role in regulating $E N a C$ make $N E D D 4 L$ a candidate gene for this disorder.

European Journal of Human Genetics (2001) 9, 922-930.

Keywords: NEDD4; NEDD4L; chromosome 18; exon mapping; cDNA cloning

*Correspondence: H Chen and M G Mclnnis, Meyer 4-141, Department of Psychiatry and Behavioral Sciences, Johns Hopkins University School of Medicine, 600 N. Wolfe Street, Baltimore, Maryland, MD 21278-7463, USA. Tel: 410614 4728; Fax: 410614 1530;

E-mail: hc@jhmi.edu; mmcinnis@jhmi.edu

Received 10 August 2001; revised 11 October 2001; accepted 21 October 2001

\section{Introduction}

NEDD4 was first identified as one of the developmentally down-regulated genes expressed in mouse neural precursor cells using a subtraction cloning approach. ${ }^{1}$ Subsequently, NEDD4 orthologues have been identified in human, mouse, rat, Xenopus and Yeast. ${ }^{2-7}$ The sequence structure of the NEDD4 gene family is highly conserved in different species, and is characterised by the presence of a $\mathrm{Ca}^{2+} /$ lipid-binding domain (the $\mathrm{C} 2$ domain), multiple protein-protein interaction modules of 35-40 amino acid residues (the WW 
domains), and a HECT (homologous to E6-AP carboxy terminus) ubiquitin-protein ligase domain at the C-terminal (reviewed by Harvey and Kumar). ${ }^{8}$ Functional studies showed that NEDD4 gene products have ubiquitin-protein ligase activity. ${ }^{9-11}$ The WW domains of NEDD4 gene family have been demonstrated to interact with the epithelial sodium channel $(E N a C)$ through the proline-rich PY motifs (eg XPPxY) within the C-termini of $E N a C$ subunits, and thereby to down regulate the intracellular $\mathrm{Na}^{+}$concentration. ${ }^{5,12-15}$ The $\mathrm{C} 2$ domain of NEDD4 has been shown to mediate $\mathrm{Ca}^{2+}$-dependent plasma membrane localisation of the protein through phospholipid binding. ${ }^{16}$ The WW domains of NEDD4 have also been shown to bind to phosphoserine and phosphothreonine residues. ${ }^{17}$ Thus, NEDD4 family genes may not only interact with proteins containing PY motifs, but also with serine- and threonine-phosphorylated proteins, and therefore regulate a much larger repertoire of protein substrates.

In mice, Nedd 4 has two distinct isoforms: Nedd4-1 that belongs to the typical NEDD4 class; and Nedd4-2 that is homologous to Nedd4-1 but lacks the C2 domain. It has recently been reported that it is Nedd4-2, but not Nedd4-1 interacts with and regulates the $E N a C$ channel activity when co-expressed in Xenopus Oocytes. ${ }^{3}$

We cloned the full-length cDNA of the human homologue of mouse Nedd4-2 during the course of performing exon trapping ${ }^{18}$ and cDNA cloning to identify candidate genes for screen for genetic variations in bipolar disorder on chromosome $18 \mathrm{q} 21 .^{19,20}$ Among the exons identified, ${ }^{21}$ four were identical to portions of three GenBank published partial cDNA sequences (AB007899, BC000621, AL137469), and to a number of ESTs (for example: R19489, T74302, R07229 and W87678). The longest is AB007899 (KIAA0439) that has 4879 base pairs and contains an ORF of 2985 bp with undetermined translation initial site. Sequence analysis showed that KIAA0439 is strongly homologous to mouse Nedd4-2. However, it is not clear whether KIAA0439 contains the C2 domain since its full-length cDNA sequence is not completely elucidated, even though there is evidence showing that the WW domain region of KIAA0439 plays a dominant negative role in $E N a C$ regulation. ${ }^{22}$ It is highly possible that there are two distinct isoforms of human NEDD4 genes that have sequence homology, but differ in the presence or lacking of the $\mathrm{C} 2$ domain.

To obtain the full-length cDNA of this novel human NEDD4 like gene (termed NEDD4L), we sequenced a corresponding EST clone (W87678), and used 5' and $3^{\prime}$ end RACE (rapid amplification of cDNA ends) to determine the full-length cDNA sequence. We submitted the full-length cDNA sequence of NEDD4L (AF210730) to GenBank in 1999. However, we observed that NEDD $4 L$ has multiple transcripts variably expressed in the tissues tested by Northern blot and RT - PCR analyses. Here we report full-length cDNA cloning, genomic structure and expression analysis of NEDD $4 L$, and mutation screening in the coding region of $N E D D 4 L$ in bipolar probands.

\section{Materials and methods}

Exon trapping and identification of NEDD4L

Exon trapping ${ }^{18}$ was carried out as described by Chen et al ${ }^{21}$ to identify the genes on human chromosome 18 (HC18) using cosmids isolated from an HC18-specific library LL18NC02. Sequence similarity database searches were performed using BLAST algorithms. ${ }^{23}$ Among the trapped exons, four showed sequence homology to NEDD4 gene orthologues across species. These exons are also identical to a number of human ESTs and to regions of a GenBank published partial cDNA sequence KIAA0439 (accession no. AB007899). KIAA0439 is a 4879 base pair sequence without the $5^{\prime} \mathrm{UTR}$ and translation start site determined. To clone the full-length cDNA of this novel gene (named NEDD4L), a corresponding EST clone (accession no.W87678) was ordered from Research Genetics and its 900 bp insert was sequenced. The full-length cDNA sequence of this novel NEDD4L gene was obtained using RACE. Primer NEDD4L.R1 (AGGAAGTAGTTCTGTGAATCCCTC) used in RACE was designed according to the most $5^{\prime}$ end sequence of the EST clone, and $5^{\prime}$ end RACE was carried out on double-stranded cDNA derived from foetal brain and placenta polyA ${ }^{+}$RNA (Clontech) using the Marathon cDNA amplification kit (Clontech cat no. K18021-1). The RACE product was subcloned into vector pBluescript $\mathrm{SK}^{+}$, and two clones were sequenced on an ABI3700 automated sequencer at the Johns Hopkins Genetics CORE facility.

Expression analysis, alternative splicing detection, and $5^{\prime}$ and $3^{\prime}$ UTR determination

The insert of EST clone (GenBank no. W87678) was used as a probe to hybridise commercial Northern blots (Clontech cat nos. 7760-1, 7756-1). The probe was labelled with ${ }^{32} \mathrm{P}$ and hybridised to the blots according to the manufacturer's protocol (PT1200-1). Post-hybridisation wash was carried out as follows: 30 min wash twice at room temperature in $2 \times$ SSC with $0.1 \%$ SDS, $30 \mathrm{~min}$ wash twice at $65^{\circ} \mathrm{C}$ in $0.1 \times \mathrm{SSC}$ with $0.1 \%$ SDS. The filters were then exposed to an X-ray film to obtain autoradiograph.

During sequencing of the 5' end RACE product of NEDD4L, an alternative splicing event was observed. To further analyse this alternative splicing event, RT - PCR was used to amplify cDNA templates derived from polyA ${ }^{+}$RNA from human foetal brain, adult brain, heart, kidney, placenta, testis (Clontech), and total RNA isolated from lymphoblast cell lines and blood. The primers used in RT-PCR were NEDD4L.F2 (5' AGACTCTCTCGGTCTGGCTC), and NEDD4L.R2 (5' TGTTATGATTGACATAGTATGTGC). Betaactin cDNA was simultaneously amplified as a means of control to compare the intensity of amplification of NEDD $4 \mathrm{~L}$ in RT-PCR analysis.

Using Northern blot analysis we did not detect an mRNA species of $4.8 \mathrm{~kb}$ presumably corresponding to KIAA0439, instead a $3.4 \mathrm{~kb}$ band in heart and muscle, and a $3.2 \mathrm{~kb}$ band and/or an additional $3.6 \mathrm{~kb}$ band in other tissues tested were 
observed. We performed a closer $5^{\prime}$ and $3^{\prime}$ RACE on double strand cDNA templates derived from polyA ${ }^{+}$RNA from human adult brain, heart, and placenta using primers NEDD4L.R3 (5'TCATTCCATTTTGGGTTCAG), and NEDD4L.F3 (5' TCGCCTTGACTTACCTCCAT) from exon 3 and the last exon of $N E D D 4 L a$, respectively. The RACE products were directly sequenced.

\section{Chromosome localisation and genomic structure of NEDD4L}

The mapping of NEDD4L to chromosome 18 was carried out in two ways. First, PCR amplification of the GeneBridge 4 mapping panel ${ }^{24}$ was performed using primers E2E11F 5' GTTCCAATGGTCCTCAGCTG and E2E11R 5' CATGTGTGAGCTCTGGGCAG derived from trapped exon E2E11. Second, BLAST ${ }^{23}$ GenBank database searches at the National Center for Biological Information (NCBI) was performed to identify any genomic sequences containing the NEDD $4 L$ gene. The identified genomic sequence contig NT_0019090.3 was used to map the exon-intron structure of the novel NEDD4L gene.

\section{Mutation screen in selected bipolar subjects}

Total RNA of lymphoblast cell lines derived from bipolar probands was isolated using Trizol reagent according to the supplied protocol (Life Technologies, cat no. 15596-026), and $5 \mu \mathrm{g}$ of total RNA was converted to first strand cDNA using the Preamplification System (Life Technology, cat no. 18089011). The coding region of NEDD4L was amplified with RTPCR from first strand cDNA using primers NEDD4L.F4 (5' TCCAGCTGAACACTTTCCAG) and NEDD4L.R4 (5' ACTCAAGCTGGGACCAGGTTC). A second round PCR (nested PCR) was performed using primers NEDD4L.F5 (5' TTAGTCACCTTCCGACAGAAG) and NEDD4L.R5 (5' CAAAAGTGCAAGCAGAAC). The PCR product was purified with the Qiaquick PCR purification kit (Cat no. 28108, Qiagene) and sequenced in the Genetics Resources Core Facility (GRCF) at Johns Hopkins University. Base calling and sequence assembly were accomplished using the Phred/Phrap/Consed package. $^{25-27}$

\section{Results}

\section{Cloning of the full-length cDNA for NEDD4L}

Exon trapping ${ }^{18}$ was used to identify genes on chromosome 18 to search for candidate genes for bipolar disorder. ${ }^{19,20}$ Sequences generated from trapped exons ${ }^{21}$ were screened against the GenBank databases (nr, dbEST, Unigene) for sequence homologies using BLAST search algorithms. ${ }^{23}$ Four of these exons (GenBank accession nos. AF149625, AF149431, AF149517, AF149521) showed identity to regions of three partial cDNA sequences published in GenBank (AB007899, BC000621, AL137469) and to a number of ESTs (for examples: R19489, T74302, R07229 and W87678). These exons also demonstrated strong homology $(83-100 \%$ at amino acid sequence level) to NEDD4 ubiquitin-protein ligase family genes identified in human, mouse, rat, Xenopus, and yeast. ${ }^{2-7}$ Sequence alignment of AB007899, BC000621, and AL137469 indicated that they are from the same gene on chromosome 18q21, and have strong homology to the NEDD4 gene family with the highest to mouse Nedd4-2 (97\% at amino acid level).

The sequences generated from the EST clone (W87678) and RACE product were used to constitute a 3246 bp full-length cDNA sequence (referred to as NEDD4La, submitted to GanBank in 1999) that contains 30 exons with an open reading frame (ORF) of 2562 nucleotides coding for a predicted polypeptide of 854 amino acids (Figure 1). The nucleotide sequence around the potential translation start site is in agreement with the conserved content of Kozak sequence. ${ }^{28}$ The polyA adenylation site (AATAAA) is located $20 \mathrm{bp}$ upstream to the end of the sequence. NEDD4La is identical from nucleotide (nt) $315-3246$ or $168-3246$ to the entire sequences of BC000621, and AL137469, respectively; and is identical from nt 136-3246 to the region of nt $244-$ 3294 in AB007899 (KIAA0439). The sequence of first $243 \mathrm{bp}$ of KIAA0439 is different from exon 1 (the first $136 \mathrm{bp}$ ) of NEDD4La. KIAA0439, BC000621 and AL137469 do not contain exon 12 of NEDD4La. In addition, KIAA0439 contains an extended 1585 bp 3' UTR sequence not seen in NEDD4La and the other two sequences BC000621 and AL137469. No additional polyA adenylation site is seen in the extended 3' UTR region of KIAA0439.

We observed that NEDD $4 L$ expressed a $3.4 \mathrm{~kb}$ mRNA species in heart and skeletal muscle, slightly longer than NEDD4La. A further 5' RACE using a primer derived form exon 3 of NEDD $4 L a$ was performed on cDNA templates derived from human brain, heart, and placenta polyA ${ }^{+}$RNA. The expected amplification of a $240 \mathrm{bp}$ fragment was seen in all three tissues, but an additional fragment about 480 bp was amplified only in heart (Figure 3B). Direct sequencing of the 480 bp 5' RACE product showed that it shares exon 2 and down stream sequence with NEDD4La, but contains two additional exons in the most $5^{\prime}$ end that are different from exon 1 of NEDD4La and KIAA0439. The transcript expressed in heart is termed NEDD4Lb. When performing 3' RACE with a primer in the last exon of NEDD4La (see Materials and methods), two fragments were amplified (Figure 3B). Sequencing analysis revealed that the shorter fragment (an expected amplification of $400 \mathrm{bp}$ ) is identical to the $3^{\prime}$ end of NEDD4La and AL137469; while the longer fragment has $130 \mathrm{bp}$ extended from the 3'UTR of NEDD4La. This 3'UTR extension is also seen in sequence BC000621. NEDD4Lb was assembled to constitute the $130 \mathrm{bp}$ extended $3^{\prime}$ UTR that shares the same polyA adenylation signal seen in NEDD4La.

The deduced polypeptide sequence of $N E D D 4 L$ was predicted to contain $4 \mathrm{WW}$ domains and an HECT ubiquitin-protein ligase domain (ScanProsite tool, http:// www.expasy.ch/tools/scnpsite.html) highly conserved features in the NEDD4 gene family. However, NEDD4L lacks the 

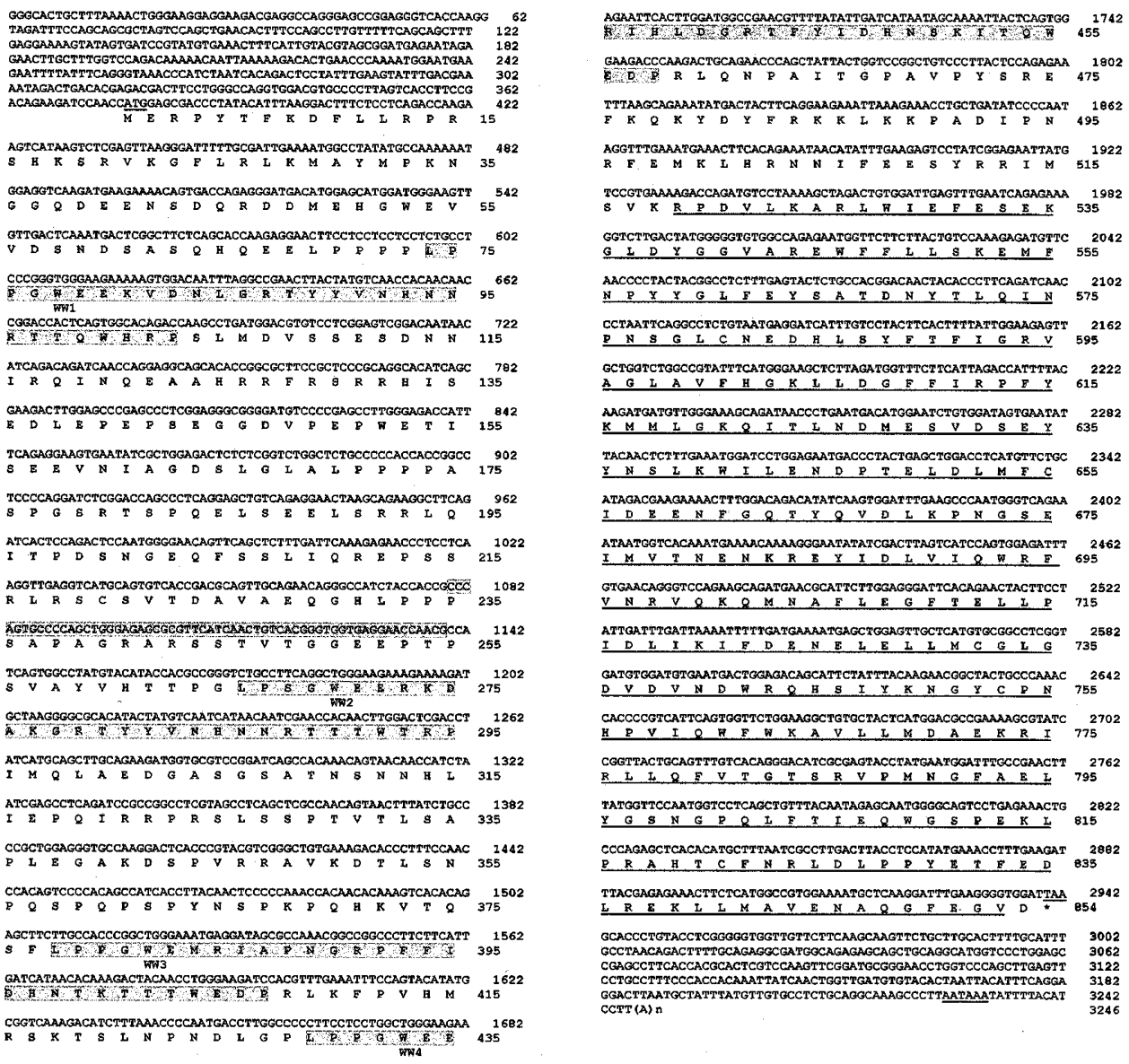

Figure 1 The nucleotide and predicted polypeptide sequences of NEDD4La. The predicted translation initiation site, the stop codon, and the polyA adenylation site are underlined. The $60 \mathrm{bp}$ alternative spliced sequence are highlighted on the nucleotide sequence, also highlighted are the four potential WW domains. The ubiquitin-protein ligase homologous region in the C-terminus is underlined.

C2 domain presenting in NEDD4. BLAST search of GenBank databases showed that NEDD4L has 97 and $62 \%$ amino acid sequence identity to mouse Nedd4-2 and human NEDD4, respectively. It is also strongly homologous to NEDD4 orthologues identified in other species. Figure 2 shows the amino acid sequence alignment of $N E D D 4 L$ to selected other members of the NEDD4 gene family from several species.

\section{Expression analysis and alternative splicing of NEDD4L}

Using the sequenced EST clone as a probe to hybridise a Northern blot indicated that this novel NEDD4L gene has transcripts of 3.2, 3.4, and $3.6 \mathrm{~kb}$ expressed differently in the tissues examined (Figure 3A). In heart and muscle, a $3.4 \mathrm{~kb}$ band was observed, while a $3.2 \mathrm{and} /$ or a less intense $3.6 \mathrm{~kb}$ band were seen in other tissues examined. The $4.8 \mathrm{~kb}$ band corresponding to the size of KIAA0439 was not detected on the tissues examined (Figure 3A).

An alternative splicing event involving exon 12 of $60 \mathrm{bp}$ was observed through sequencing analysis of $5^{\prime}$ end RACE and RT-PCR amplification (Figures 1 and 3C). Both alternative spliced forms of NEDD4L were expressed, however, the shorter allele without the $60 \mathrm{bp}$ is predominantly present in several tissues (human foetal and adult brain, kidney, placenta, and lymphoblast cell lines), while the longer allele is predominantly expressed in kidney and placenta, but hardly detectable in foetal and adult brain (Figure 3C). Therefore, 18 forms of NEDD $4 L$ transcripts could potentially be produced to encode the novel human NEDD4 like ubiquitin-protein ligase if all possible combinations of the three different $5^{\prime}$ UTR and three different $3^{\prime}$ UTR together with the alternative events seen in NEDD4La, NEDD4Lb, and KIAA0439 (referred to here as NEDD4Lc) could occur in cells.

\section{Chromosome localisation and genomic structure of NEDD4L}

A trapped exon ${ }^{21}$ (E2E11) of NEDD4L was mapped to $18 \mathrm{q} 21$ between markers D18S1117 and D18S64 using PCR amplification of the GeneBridge4 mapping panel. ${ }^{24}$ BLAST database search identified a genomic sequence contig NT_010909.3 in the $18 \mathrm{q} 21$ region that has $486511 \mathrm{bp}$ and contains all the 


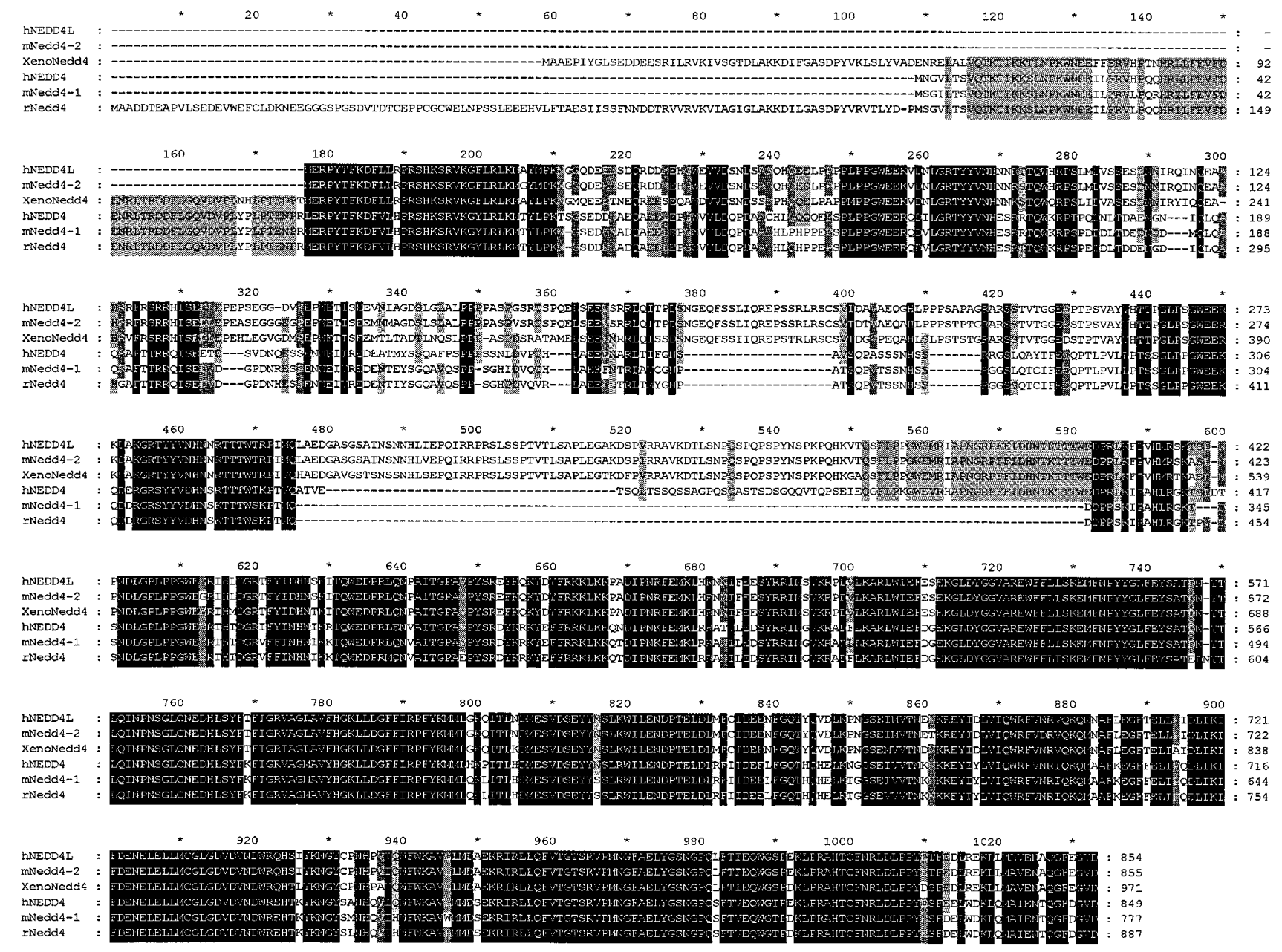

Figure 2 Multiple sequence comparison of NEDD4L with orthologues of NEDD4 from different species. The alignment was generated using CLUSTAL W (http://www2.ebi.ac.uk/clustalw/) and was shaded using the Genedoc program. ${ }^{34}$ Note: symbols hNEDD4L, mNedd4-2, XenoNedd4, hNEDD4, mNEdd4-1, and rNedd4 represent human NEDD4L, mouse Nedd4-2, Xenopus Nedd4, human NEDD4, mouse Nedd4-1, and rat Nedd4, respectively.

exons of NEDD4La. We observed that the first exon (exon 1a) of NEDD4La is identical to base pair 181446-181581 of NT_010909.3, while the 'first' exon (exon 1c) of NEDD4Lc is located $26 \mathrm{~kb}$ upstream of that of NEDD4La. The first exon (exon 1b) of NEDD4Lb is not contained in NT_001909.3, however, its first intron ends at nucleotide 125718 in NT_001909.3, and its second exon (exon 2b) is located at least $55 \mathrm{~kb}$ upstream of exon 1a in NT_001909. Table 1 lists the sizes of each exon, the exon-intron boundary sequences, and the intron ranges of NEDD4L in NT_010909.3.

\section{Mutation screen in bipolar subjects}

Since NEDD4L maps to the region of $18 \mathrm{q} 21$ showing linkage evidence for a susceptibility locus for bipolar disorder, ${ }^{19,20}$ three unrelated bipolar I probands and their parents were screened for mutation in the ORF of NEDD4L. RT - PCR was performed to amplify the cDNA coding sequence from total
RNA isolated from lymphoblast cell lines derived from these individuals. Direct sequencing of the PCR products did not indicate variations (mutations) in the nine individuals tested. A semi-quantitative RT - PCR amplification analysis (normalised to the beta-actin amplification product) did not indicate an expression reduction of NEDD $4 L$ in lymphoblast cell lines derived from members of three families including subjects with bipolar disorder and unaffected relatives (data not shown).

\section{Discussion}

The full-length cDNA for a novel gene NEDD $4 L$ in the region of 18q21 has been characterised. The genomic structure of NEDD4L and its tissue expression pattern were also determined. The alternative splicing event of NEDD $4 L$ involving exon 12 has a tissue-specific pattern in that the 


\section{A. Northern blot analysis of NEDD4L}

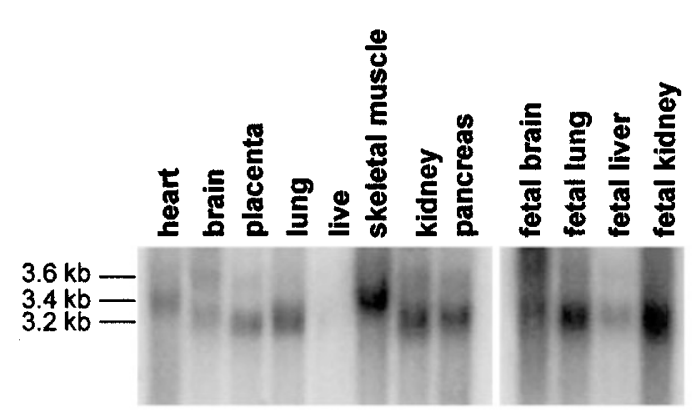

\section{B. 5' and 3' RACE analysis of NEDD4L}

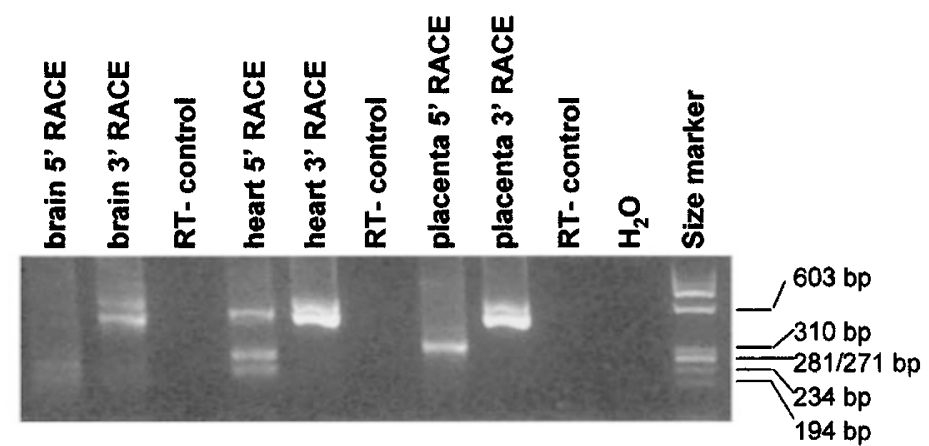

\section{NEDD4L alternative splicing event detected by RT-PCR analysis}

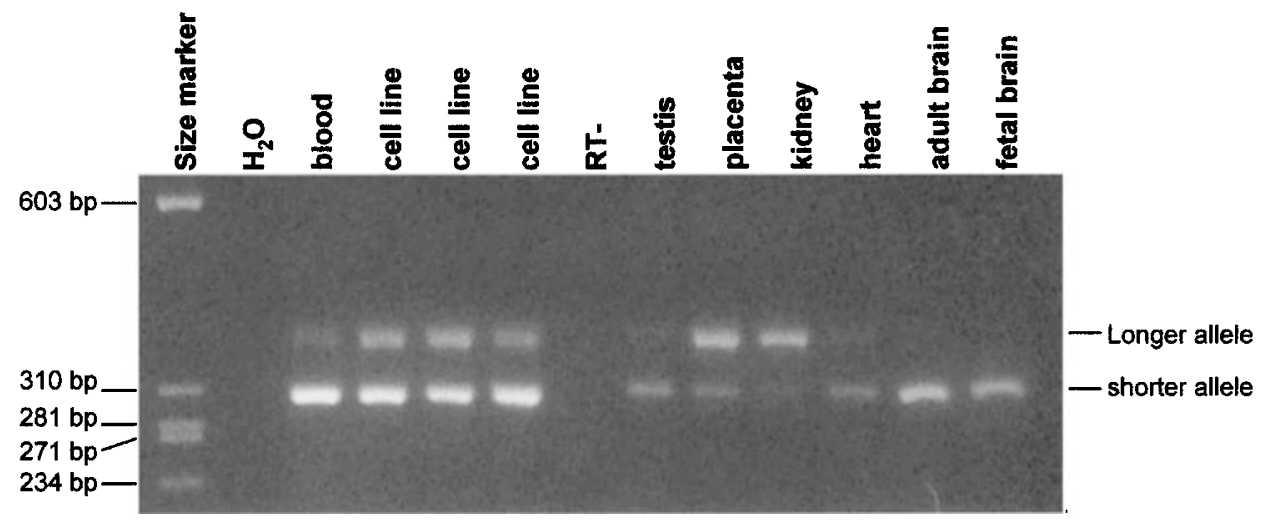

Figure 3 (A) Northern blot analysis. Northern blots (MTN, Clontech cat nos. 7760-1, 7756-1) were used to determine the expression pattern of NEDD4L. Each lane of the MTN blots contains $2 \mu \mathrm{g}$ polyA ${ }^{+}$RNA. On the top of each blot the types of tissues are indicated. The arrows show the 3.2, 3.4, and $3.6 \mathrm{~kb}$ mRNA species detected with EST clone W87678 as hybridisation probe. (B) RACE amplification of the most $5^{\prime}$ and $3^{\prime}$ ends of NEDD4L. The tissue types, $5^{\prime}$ and $3^{\prime}$ RACE are shown on the top of the panel, RT - indicates a control sample used in reverse transcription without the addition of reverse transcriptase in the reaction. (C) RT-PCR analysis of exon 12 alternative splicing. Shown are analysed RNA samples from 10 different tissues. RT - indicates a reverse transcription negative control sample.

exon 12 minus form is predominantly present in brain and lymphocytes while the exon 12 plus form is strongly seen in kidney and placenta. Striking sequence homology to mouse Nedd4-2 suggests that NEDD4L is the human homologue of the mouse Ubiquitin-protein ligase Nedd4-2.

The 30 exons of NEDD4L are distributed in at least $356 \mathrm{~kb}$ genomic region. Exons $2-30$ are shared by NEDD4La, $b$ and $c$ except 12 involved in an alternative splicing event. The first exon (plus exon 2 in NEDD4Lb) has difference sequences in all these transcripts identified and is located in different upstream regions on genomic sequence. This observation indicates that there might be multiple promoters involved in NEDD $4 L$ transcription, and might explain the tissue-specific expression pattern of NEDD $4 L$.
Ubiquitin-protein ligase NEDD4 homologues have been demonstrated in human, mouse, rat, and Xenopus to interact, through their WW domains, with the proline-rich PY motifs (xPPxY) of the epithelial sodium channel ENaC and to down regulate the channel's activity. ${ }^{5,10,12-14,29}$ Mutations or deletions of the PY motifs of $E N a C$ prevent interaction of $N E D D 4$ with $E N a C$, and thus lead to Liddle's syndrome (an autosomal dominant inheritance form of hypertension). ${ }^{5}$ In addition, the WW domains of NEDD4 have been shown to bind to the phosphorylated serine and threonine residues of substrate proteins. ${ }^{17}$ Therefore, the NEDD4 gene family may have a wide range of functional interaction with proteins containing PY motifs and serine- and threonine-phosphorylated proteins. 
Table 1 Genomic structure of NEDD4L. Sequences shown are flanking regions of exon-intron junctions. Capital letters indicate regions of exons, and subscript cases show splicing donor and acceptor sites. The intron ranges indicated refer to NCBI's contig sequence NT_010909.3

\begin{tabular}{|c|c|c|c|c|c|}
\hline $\begin{array}{l}E x C \\
D D 4\end{array}$ & $\begin{array}{l}\text { three } \\
\text { EDD4L }\end{array}$ & $\begin{array}{l}\text { ripts } \\
\text { IAA0439 }\end{array}$ & Exon size $b p$ & Exon-intron boundary sequence (exon/5' intron $3^{\prime} /$ exon) & $\begin{array}{c}\text { Intron range in } \\
\text { NT_010909.3 }\end{array}$ \\
\hline & $1 \mathrm{~b}$ & - & $1-298$ & exon1b ... TCTGTCCACTTTGTAGAAG/ ? ... intron1b ... TсстTCTCACAG/GGAGAGTCCCGT ... exon2b 5' & $?-125713$ \\
\hline & $2 b$ & - & $299-372$ & exon2b 3' ... CTTTGGAGCCAG/СTATGTTGGCTT ... intron $2 b$... ATTाTCTTACAG/TGATCCGTATGT ... exon2a 5' & $125788-205250$ \\
\hline & - & 1c & $1-244$ & exon1c ... GCCTGGAATCTG/GTAAGTGCCACC ... intronic ... ATTTTCTTACAG/TGATCCGTATGT ... exon2a 5' & $155333-205250$ \\
\hline & - & - & $1-136$ & exon1 a ... GGAAAAGTATAG/GTAAGAACAAAG ... intronia ... ATाTCTTACAG/TGATCCGTATGT . .. exon2a 5' & $181582-205250$ \\
\hline & $2 a$ & $2 a$ & $137-218$ & exon2a $3^{\prime} \ldots$ ACAATTAAAAAG/GTAGGTGTCGAT ... intron2b ... пाтTCтTCCAG/ACACTGAACCCA ... exon3 5' & $205333-208722$ \\
\hline & 3 & 3 & $219-257$ & exon3 $3^{\prime} \ldots$ TTTTATTTCAGG/GTAAGTTाTTCA ... intron3 ... TGTTCCTATAG/GTAAACCCATCT ... exon $45^{\prime}$ & $208762-211824$ \\
\hline & 4 & 4 & $258-311$ & exon $43^{\prime} \ldots$ GAAAATAGACTG/GTAAGTGGATGC ... intron $4 \ldots$ TCTTCCTAACAG/ACACGAGACGAC ... exon5 5' & $211879-275804$ \\
\hline & 5 & 5 & $312-362$ & exon5 $33^{\prime} \ldots$ AGTCACCTTCCG/GTAAGGACAGTC ... intron5 ... TाTाCCCCACAG/TCATAAGTCTCG ... exon7 5' & $282310-283054$ \\
\hline & 6 & 6 & $363-424$ & exon6 $33^{\prime} \ldots$ CAGACCAAGAAG/GTGAGGCTTGTG ... intron6 ... TाATGTGTGCAG/TCATAAGTCTCG ... exon7 5' & $282310-283054$ \\
\hline & 7 & 7 & $425-527$ & exon7 3' ... GATGACATGGAG/GTACGTGGAGGG .... intron7 ... TाTATTCCGCAG/CATGGATGGGAA ... exon8 5' & $283158-284818$ \\
\hline & 8 & 8 & $528-694$ & exon8 $3^{\prime} \ldots$ ACCAAGCCTGAT/GTGAGTACCGTG ... intron8 ... стGCATGCTCAG/GGACGTGTCCTC $\ldots$ exon9 5 & $284986-288817$ \\
\hline & 9 & 9 & $695-827$ & exon 8 3' ... GATGTCCCCGAG/GTACGATGTCCC ... intron9 ... стTCTCTGAAAG/CCTTGGGAGACC . . exon10 5' & $288951-290560$ \\
\hline & 10 & 10 & $828-1004$ & . AGCTCTTTGATT/GTAAGTAGTGGC ... intron10 ... СTCTCCTTCCAG/CAAAGAGAACCC ... exon $115^{\prime}$ & $290738-293640$ \\
\hline & 11 & 11 & $1005-1079$ & exon11 $3^{\prime} \ldots$ CATCTACCACCG/GTAACCCATGCT ... intron $11 \ldots$ TATCATTCACAG/CCCAGTGCCCCA ... exon12 5' & -295300 \\
\hline & 12 & - & $1080-1139$ & exon12 $33^{\prime} \ldots$ GAGGAACCAACG/GTAATGATCCAC ... intron $12 \ldots$ TGCACAAACAG/CCATCAGTGGCC ... exon13 5' & -30086 \\
\hline & 13 & 13 & $40-1271$ & exon13 $33^{\prime} \ldots$ CCTATCATGCAG/GTACGAAGATTG ... intron $13 \ldots$ CCTCCAAAATAG $/ C T T G C A G A A G A T \ldots$ exon $145^{\prime}$ & 301450 \\
\hline & 14 & 14 & $1272-1391$ & exon $143^{\prime} \ldots$ GCCCCGCTGGAG/GTGAGACGGCTA ... intron $14 \ldots$ GTTATTCTTTAG/GGTGCCAAGGAC $\ldots$ exon15 5' & 02728 \\
\hline & 15 & 15 & $1393-1589$ & exon15 3' ... ACTACAACCTGG/GTAAGGCTGCTG ... intron15 ... тाтाтTाGCAG/GAAGATCCACGT ... exon16 5' & $302927-30935$ \\
\hline & 16 & 16 & $1590-1667$ & exon16 $33^{\prime} \ldots$ GGCCCCCTTCCT/GTGAGTACACTG ... intron $16 \ldots$ CCCGGATACTAG/CCTGGCTGGGAA ... exon17 5' & $309438-310813$ \\
\hline & 17 & 17 & 1668 & exon17 $3^{\prime} \ldots$... ATATTGATCATA/GTAAGTAGGCGC ... intron7 ... AACATTTCAGA/TAGCAAAATTAC . . exon18 5' & 310 \\
\hline & 19 & 19 & $1782-1847$ & exon19 $33^{\prime} \ldots$ TTAAAGAAACCT/GTGAGTAATCAT ... intron $19 \ldots$ TCTाTGTGTAG/GCTGATATCCCC ... exon20 5' & $324157-32582$ \\
\hline & 20 & 20 & $1848-2077$ & exon20 3'GTACTCTGCCAC/ СTAAGTATATGG .... intron20 ... TCTCCTCAAAAG/GGACAACTACAC ... exon $215^{\prime}$ & 326 \\
\hline & 21 & 21 & $2078-2199$ & АGTCTTGAA ... intron21 ... ACCGTGTTTTAG/GTTTCTTCATTA ... exon22 5' & $327691-33021$ \\
\hline & 22 & 22 & $2200-2270$ & exon22 $3^{\prime} \ldots$ ATGGAATCTGTG/GTAAGTAAATGC ... intron $22 \ldots$ GTCATTCTGTAG/GATAGTGAATAT $\ldots$ exon $235^{\prime}$ & $330291-33299$ \\
\hline & 23 & 23 & $2271-2366$ & exon23 $33^{\prime} \ldots$ AACTTTGGACAG/ СTACATGTGGGT ... intron $23 \ldots$ TाGTAATTACAG/ACATATCAAGTG ... exon24 5' & $333093-34306$ \\
\hline & 24 & 24 & $2367-2440$ & exon24 3' ... GGAATATATCGA/ GTATGTATACAC ... intron24 ... тाTCTCCTGCAG/CTTAGTCATCCA ... exon25 5' & 3431 \\
\hline & 25 & 25 & $2441-2501$ & exon25 $33^{\prime} \ldots$ GCCTTCTTGGAG/GTAAGCCATGCT ... intron25 ... TाTाTCTTCAG/GGATTCACAGAA ... exon26 5' & $345409-34726$ \\
\hline & 26 & 26 & $2502-2561$ & exon $263^{\prime} \ldots$ AATGAGCTGGAG/GTाGTATTATA ... intron $26 \ldots$ пाтCTाCCTAG/TTGCTCATGTGC $\ldots$ exon27 5' & $347322-34890$ \\
\hline & 27 & 27 & $2562-2669$ & exon26 3' ... CGTCATTCAGTG/GTCTGGAAGGT ... intron $27 \ldots$ стстGTTCATAG/GTCTGTGCTACTC $\ldots$ exon28 5' & $349016-35046$ \\
\hline & 28 & 28 & $2670-2766$ & exon27 3' ... CCGAACTTTATG/GTGAGCAGGATA ... intron28 ... TाTCTTGTCTAG/GTTCCAATGGTC ... exon29 5' & $350566-35130$ \\
\hline & 29 & 29 & $2767-2839$ & exon29 $3^{\prime} \ldots$ AGCTCACACATG/GTGAGTGACAAA ... intron29 ... тाсCтाTTGCAG/CTTTAATCGCCT ... exon30 5' & $351383-355989$ \\
\hline
\end{tabular}

*Indicates the range of exon 30 of NEDD4La, see text for details of exon 30 in NEDD4Lb and c. 
Recently, the mouse Nedd4-2 gene has been identified from a cell line derived from cortical collecting duct. ${ }^{3}$ Unlike mouse Nedd4-1 that features having $3 \mathrm{WW}$, one C2, and one HECT domain, Nedd4-2 contains $4 \mathrm{WW}$ and a HECT domain, but lacks the C2 domain in the N-terminus. Both Nedd4- 1 and 2 are expressed in the cortical collecting duct cells, however, it is thought that Nedd4-2 is the real regulator of the ENaC channel and a potential candidate for arterial hypertension since it is Nedd4-2, not Nedd4-1 interacting with the ENaC when coexpressed in Xenopus oocytes. ${ }^{3}$ The human novel NEDD4L gene showed $97 \%$ amino acid sequence identity to mouse Nedd4-2, and has similar protein structure modules as mouse Nedd4-2 (containing one HECT and four WW domains, lacking the C2 domain). These properties suggest that NEDD $4 L$ is the human homologue of mouse Nedd4-2. A recombinant protein containing only the WW domains of KIAA0439 (NEDD4LC) has recently been reported to act as a dominant negative mutant that can interfere with the $\mathrm{Na}^{+}$-dependent feedback inhibition of the $E N a C$ in whole-cell patch clamp experiments, which suggests NEDD4 and NEDD4L either play a redundant role in $E N a C$ regulation or function in a tissue- and/or signalspecific manner to down-regulate $E N a C .^{22}$

There are several genetic disorders mapped to 18q21, including autosomal dominant orthostatic hypotensive disorder, ${ }^{30}$ a locus for postural systolic blood pressure response, ${ }^{31}$ IDDM6, ${ }^{32}$ Grave's disease (GD), $^{33}$ and bipolar disorder. ${ }^{19,20}$ The genes for these disorders are currently unidentified. Sequence analysis in bipolar subjects from families linked to $18 \mathrm{q} 21^{19,20}$ did not reveal variation in the protein-coding region of $N E D D 4 L$. Semi-quantitative RT - PCR analysis did not indicate a reduction of $N E D D 4 L$ in the bipolar subject tested. However, to exclude the gene to be responsible for bipolar disorder, sequence variation in introns, splicing sites, and promoter region need to be further studied. Multi-point linkage analysis in $74 \mathrm{sib}$ pairs of GD cases showed a peak NPL score of $3.09(P=0.001)$ at marker D18S487. ${ }^{33}$ In IDDM6, there is evidence for linkage disequilibrium at marker D18S487 as well. ${ }^{32}$ Given that NEDD4L is located 6 cM distal to D18S487, it is unlikely that $N E D D 4 L$ is responsible for IDDM6 or GD.

Does NEDD4L play a role in orthostatic hypotensive disorder? Linkage studies have mapped the autosomal orthostatic hypotensive disorder on $18 \mathrm{q} 21$ between markers D18S858 and D18S541. ${ }^{30}$ There is also linkage evidence that a locus close to marker D18S858 may be responsible for postural systolic blood pressure response. ${ }^{31}$ NEDD4L maps between these two markers and within $2 \mathrm{Mb}$ proximal to 18S1367. This positional evidence in combination with its potential role in regulation of the epithelial sodium channel $E N a C$ activity makes NEDD $4 L$ a candidate gene for mutation screen in orthostatic hypotensive disorder.

\section{Acknowledgments}

This study is supported by grants from the Theodore and Vada Stanley Foundation (JR De Paulo Jr, MG McInnis, and CA Ross), and from
NARSAD, the National Alliance for Research on Schizophrenia and Depression (JR De Paulo Jr, MG McInnis, and H Chen). We thank D Avramopoulos for critical reading of the manuscript. We are grateful to Dr Paul McHugh and the Department of Psychiatry for the support of this work.

\section{Accession number}

The sequences reported here have GenBank nos. AF210730 (NEDD4La), AF385931 (NEDD4Lb). The LL18NCO2 cosmid library was constructed in the Lawrence Livermore National Laboratory, and distributed by UK HGMP Resource Center.

\section{References}

1 Kumar S, Tomooka Y, Noda M: Identification of a set of genes with developmentally down-regulated expression in the mouse brain. Biochem Biophys Res Commun. 1992; 185: 1155-1161.

2 Nagase T, Miyajima N, Tanaka A et al: Prediction of the coding sequences of unidentified human genes. III. The coding sequences of 40 new genes (KIAA0081-KIAA0120) deduced by analysis of cDNA clones from human cell line KG-1. DNA Res 1995; $2: 37-43$.

3 Kamynina E, Debonneville C, Bens M, Vandewalle A, Staub O: A novel mouse Nedd4 protein suppresses the activity of the epithelial Na+ channel. FASEB J 2001; 15: 204-214.

4 Kumar S, Harvey KF, Kinoshita M, Copeland NG, Noda M, Jenkins NA: cDNA cloning, expression analysis, and mapping of the mouse Nedd4 gene. Genomics 1997; 40: 435 - 443.

5 Staub O, Dho S, Henry P et al: WW domains of Nedd4 bind to the proline-rich PY motifs in the epithelial $\mathrm{Na}+$ channel deleted in Liddle's syndrome. EMBO J 1996; 15: 2371 - 2380.

6 Rebhun JF, Pratt JH: Molecular cloning of Nedd4 from Xenopus laevis. DNA Seq 1998; 9: 295-306.

7 Hein C, Springael JY, Volland C, Haguenauer-Tsapis R, Andre B: NPl1, an essential yeast gene involved in induced degradation of Gap1 and Fur4 permeases, encodes the Rsp5 ubiquitinprotein ligase. Mol Microbiol 1995;18: 77-87.

8 Harvey KF, Kumar S: Nedd4-like proteins: an emerging family of ubiquitin-protein ligases implicated in diverse cellular functions. Trends Cell Biol 1999; 9: 166-169.

9 Staub O, Gautschi I, Ishikawa T: Regulation of stability and function of the epithelial $\mathrm{Na}+$ channel $(\mathrm{ENaC})$ by ubiquitination. ЕМВO J 1997; 16: $6325-6336$.

10 Abriel H, Kamynina E, Horisberger JD, Staub O: Regulation of the cardiac voltage-gated $\mathrm{Na}+$ channel (H1) by the ubiquitinprotein ligase Nedd4. FEBS Lett 2000; 466: 377-380.

11 Springael JY, De Craene JO, Andre B: The yeast Npi1/Rsp5 ubiquitin ligase lacking its $\mathrm{N}$-terminal $\mathrm{C} 2$ domain is competent for ubiquitination but not for subsequent endocytosis of the gap1 permease. Biochem Biophys Res Commun 1999; 257: 561 566.

12 Schild L, Lu Y, Gautschi I, Schneeberger E, Lifton RP, Rossier BC: Identification of a PY motif in the epithelial $\mathrm{Na}$ channel subunits as a target sequence for mutations causing channel activation found in Liddle syndrome. EMBO J 1996; 15: 2381 2387.

13 Abriel H, Loffing J, Rebhun JF et al: Defective regulation of the epithelial $\mathrm{Na}+$ channel by Nedd4 in Liddle's syndrome. J Clin Invest 1999; 103: 667-673.

14 Harvey KF, Dinudom A, Komwatana P et al: All three WW domains of murine Nedd 4 are involved in the regulation of epithelial sodium channels by intracellular $\mathrm{Na}+$. J Biol Chem 1999; 274: $12525-12530$

15 Snyder PM, Olson DR, McDonald FJ, Bucher DB. Multiple WW domains, but not the $\mathrm{C} 2$ domain, are required for the inhibition of ENaC by human Nedd4. J Biol Chem 2001; 276: 28321 - 28326. 
16 Plant PJ, Yeger H, Staub O, Howard P, Rotin D: The C2 domain of the ubiquitin protein ligase Nedd 4 mediates Ca2+- dependent plasma membrane localization. J Biol Chem 1997; 272: 32329 32336.

17 Lu PJ, Zhou XZ, Shen M, Lu KP: Function of WW domains as phosphoserine- or phosphothreonine-binding modules. Science 1999; 283: 1325 - 1328.

18 Buckler AJ, Chang DD, Graw SL et al: Exon amplification: a strategy to isolate mammalian genes based on RNA splicing. Proc Natl Acad Sci USA 1991; 88: 4005 - 4009.

19 Stine OC, Xu J, Koskela R et al: Evidence for linkage of bipolar disorder to chromsome 18 with a parent-of-origin effect. $A m \mathrm{~J}$ Hum Genet 1995; 57: 1384-1394.

20 McMahon FJ, Hopkins PJ, Xu J et al: Linkage of bipolar affective disorder to chromosome 18 markers in a new pedigree series. Am J Hum Genet 1997; 61: 1397 - 1404.

21 Chen H, Huo Y, Patel S et al: Gene identification using exon amplification on human chromosome 18q21: implications for bipolar disorder. Mol Psychiatry 2000; 5: 502-509.

22 Harvey KF, Dinudom A, Cook DI, Kumar S: The Nedd4-like protein KIAA0439 is a potential regulator of the epithelial sodium channel. J Biol Chem 2001; 276: 8597-8601.

23 Altschul SF, Gish W, Miller W, Myers EW, Lipman DJ: Basic local alignment search tool. J Mol Biol 1990; 215: 403 - 410.

24 Gyapay G, Schmitt K, Fizames C et al: A radiation hybrid map of the human genome. Hum Mol Genet 1996; 5: 339-346.

25 Gordon D, Abajian C, Green P: Consed: a graphical tool for sequence finishing. Genome Res 1998; 8: 195-202.

26 Ewing B, Green P: Base-calling of automated sequencer traces using phred. II. Error probabilities. Genome Res 1998; 8: 186194.
27 Ewing B, Hillier L, Wendl MC, Green P: Base-calling of automated sequencer traces using phred. I. Accuracy assessment. Genome Res 1998; 8: 175 - 185.

28 Kozak M: Structural features in eukaryotic mRNAs that modulate the initiation of translation. J Biol Chem 1991; 266 : $19867-19870$.

29 Dinudom A, Harvey KF, Komwatana P, Young JA, Kumar S, Cook DI: Nedd4 mediates control of an epithelial $\mathrm{Na}+$ channel in salivary duct cells by cytosolic Na+. Proc Natl Acad Sci U S A 1998; 95: $7169-7173$.

30 DeStefano AL, Baldwin CT, Burzstyn $\mathrm{M}$ et al: Autosomal dominant orthostatic hypotensive disorder maps to chromosome 18q. Am J Hum Genet 1998; 63: 1425 - 1430.

31 Pankow JS, Rose KM, Oberman A et al: Possible locus on chromosome 18q influencing postural systolic blood pressure changes. Hypertension 2000; 36: 471-476.

32 Merriman T, Twells R, Merriman $\mathrm{M}$ et al: Evidence by allelic association-dependent methods for a type 1 diabetes polygene (IDDM6) on chromosome 18q21. Hum Mol Genet 1997; 6: 1003 1010.

33 Vaidya B, Imrie $\mathrm{H}$, Perros $\mathrm{P}$ et al: Evidence for a new Graves disease susceptibility locus at chromosome 18q21. Am J Hum Genet 2000; 66: 1710-1714.

34 Nicholas, KB, Nicholas Jr HB, Deerfield, II DW: GeneDoc: Analysis and Visualization of Genetic Variation. EMBNEW. NEWS 4, 14: 1997. 